\title{
FONTES DE INFORMAÇÃO ESPECIALIZADAS DE ACESSO ABERTO
}

\begin{abstract}
Juliana Fachin*
Nelma Camelo Araújo*

RESUMO O presente artigo de levantamento descritivo, trata de fontes de informação especializadas de acesso aberto. Aplica a revisão de literatura com levantamento bibliográfico e documental e descritivo. Com objetivo de verificar e descrever fontes especializadas de acesso aberto. Visa servir de reflexão a respeito do uso e difusão de fontes de acesso aberto nas redes da internet. Foram levantados setenta e um exemplos de fontes especializadas de acesso aberto em: Biblioteca Digital, Base de Dados, Diretórios, Portais, Repositórios, MetabuscadoreseBlogs. Conclui-se que, o acesso aberto propicia o compartilhamento de informações científicas e estratégicas, esse cenário permeia o uso dessas fontes pela comunidade científica e toda sociedade que tem acesso à internet. Constatou-se que é crescente o aparecimento fontes de acesso aberto em vários formatos. As que chamaram nossa atenção pela quantidade foram: bibliotecas digitais, base de dados e diretórios que dispunham materiais de acesso aberto.
\end{abstract}

Palavras-Chave:Fontes de informação especializada. Acesso aberto. Canais de comunicação formais e informais.
* Mestre em Ciência da Informação pela Universidade Federal de Santa Catarina, Brasil. Doutoranda em Ciência da Informação no Programa de Pós-Graduação em Ciência da Informação da Universidade Federal de Santa Catarina, Brasil. Bolsista Capes.

E-mail: julianafachin@gmail.com.

** Doutora em Ciência da Informação pela Universidade Federal de Santa $\mathrm{Ca}$ tarina, Brasil. Professora da Universidade Federal de Alagoas, Brasil.

E-mail: nelmacamelo@gmail.com.

\section{INTRODUÇÃO}

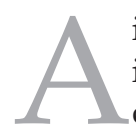

informação

é algo extremamente importante, ela impulsiona desenvolvimento, desencadeia o processo cognitivo do saber por meio da relação entre: dado $\leftrightarrow$ informação $\leftrightarrow$ conhecimento, algo intangível, no entanto, promove grande impacto na sociedade (MATHEUS, 2005).

$\mathrm{O}$ uso de informação cresce assim como o número de publicações, os usuários estão cada vez mais exigentes, querem dados rápidos, atuais e de credibilidade. Babalhavaeji e Farhadpoor (2013), More (2014) e Womble (2015) investigaram tendências de usuários ao escolher uma fonte de informação. Os estudos desses autores mostram que, fontes atualizadas (recentes) são as mais requeridas, sejam impressas ou eletrônicas. Outra questão foi a credibilidade da fonte, apontada como extremamente importante no processo de escolha. A facilidade de acesso também ganhou destaque, fontes eletrônicas são bastante visadas pelos usuários pesquisados.

São questões de grande relevância para estruturas e redes de serviços informacionais, com tanta informação disponível na internet boa parte rapidamente fica desatualizada, em especial aquelas voltadas para as novas tecnologias. O acesso à informação atual, credível e de qualidade tem implicações imediatas em todos os aspectos da vida econômica, social e científica de uma sociedade, por isso a ONU se preocupa constantemente com as redes e serviços informacionais principalmente para os países em desenvolvimento, pois sabe quão necessária e estratégica ela é.

Nem toda informação se torna insumo para a tomada de decisão. Em ciências se faz necessário o uso de fontes especializadas que impactam diretamente no processo decisor; as literaturas especializadas são organizadas e 
servem de base para obter um conhecimento específico, ex.: cenário social, econômico, mercadológicos, tendências, público alvo, entre outros. Sugahara e Jannuzzi (2005, p. 50), expõem que "As fontes [especializadas] relacionadas com as atividades de mercado são identificadas de maior relevância para inovação", assim como são para a ciência.

Castells (2015) menciona que, o uso de estruturas informacionais tem sido bastante utilizado para captar informações de todo o tipo, por vários países e em todos os continentes, muitas vezes por meio de espionagem, armazenando e cruzamento de dados, desenvolvendo um imenso banco informacional, são informações estratégicas, o conhecimento os deixa a frente dos adversários.

Neste caso, a informação representa o diferencial, determina quem deterá o conhecimento ou prática e, quem não deterá, depende só do seu acesso. Alguns movimentos a favor do acesso aberto ao conhecimento científico têm ganhado amplo espaço como o caso do COUNCIL OF THE EUROPEAN UNION Política da Comunidade Comum Europeia 2016', em aprovar o planejamento "HORIZON 2020", no qual possibilita o acesso aberto para todas as publicações científicas e aos dados de pesquisa que tenham financiamento da Comunidade Europeia.

Tudo indica que o movimento que surgiu em 2001 na conferência de Budapest Open Access Iniciative - $\mathrm{BOAI}^{2}$, em Budapeste, organizada pela Open Society Institute - OASI, está ganhando força e cada vez mais adeptos de diversas disciplinas e áreas do conhecimento ${ }^{3}$. Organismos não governamentais, empresas, instituições, voluntários de todo o mundo tem empenhado esforços para garantir que o open access ganhe proporção mundial para que o acesso ao conhecimento não seja privilégio de alguns.

Fica evidente que $o$ foco em fontes informacionais especializadas de acesso aberto, alicerçam a base para a aplicação de pesquisas e desenvolvimento da ciência em qualquer país, se torna o elemento distintivo entre o saber e o fazer.

I Veja mais sobre $\circ$ assunto em: <http://www.diretodaciencia. com/2016/05/30/uniao-europeia-quer-todos-os-seus-artigos-cientificosem-acesso-aberto-ate-2020/>

2 Veja mais sobre $\circ$ evento do BOIA em: <http://www. budapestopenaccessinitiative.org/read. >. Acesso em: 02 jan. 2017.

3 Ver mais em Kuramoto (20I2), em <https://kuramoto.wordpress. com/2012/02/27/acesso-livre-como-tudo-comecou/>
No entanto, há muitas informações disponíveis nas redes e estruturas da Web, porém, nem tudo é relevante e confiáveis para o bom emprego da ciência. Por isso, esta pesquisa pretende conhecer as fontes informacionais especializadas de acesso aberto. Por esse motivo, esta pesquisa é pertinente para a comunidade científica, visa desvelar mais sobre o campo pouco explorado das fontes informacionais especializadas de acesso aberto.

Conforme Mueller (2000, p. 31), “[...] a necessidade de se conhecer as fontes e saber identificar e promover o acesso à informação pertinente continua sendo tão importante quanto sempre foi para os profissionais que se dedicam ao atendimento do usuário".

Este artigo de levantamento descritivo, apresenta uma revisão de literatura que descreve e apresenta fontes de informação especializadas de acesso aberto. Foi feito um levantamento na internet para identificar fontes especializadas e que dispunham de informações de acesso aberto. Destacamos setenta e uma, na modalidade: Biblioteca Digital, Base de dados, Diretórios, Portais, Repositórios, Metabuscadores e Blogs. Cabe mencionar que o levantamento não teve o objetivo de ser quantitativo, mas sim de captar no mínimo cinco exemplos de aplicação no modelo Open Access, em cada tipo de fonte. Das quais, no mínimo duas deveriam ser de cunho internacional.

Como procedimento técnico é bibliográfica e documental e descritiva. Rampazzo (2013) específica que a técnica, bibliográfica, procura utilizar vários tipos de fontes, livros, artigos, publicações em meio eletrônico ou impresso; já a documental utiliza fonte primária, relatórios, leis, dados estatísticos. É feita uma breve revisão de literatura, no qual, contextualiza elementos envolvidos no tema. Descrevendo os exemplos encontrados e os contextualizando com sua característica e aplicação.

\section{INFORMAÇÃO ESPECIALIZADAS E DE ACESSO ABERTO}

Antes mesmo da datação do calendário cristão, os povos antigos já organizavam o seu conhecimento, que serviria de suporte para futuros estudos, como o caso das bibliotecas da antiguidade que continham em seu acervo 
documentos administrativos e científicos, rotas marítimas, pontos de comércio, produção e colheita, casamentos e vendas de terras, etc., registravam todo conhecimento e organização civil de seu tempo.

Perez-Rioja (1952), Martins (2002), Battles (2003), Ortega (2004) e Santos (2012), estudaram a organização das bibliotecas antigas e ambos relatam que todas tinham em comum a característica de serem centros informacionais, guardavam, organizavam todo conhecimento de sua época e do povo. No entanto, foi na idade média (meados do séc. III e IV d.c.) que os organismos religiosos, começaram a produzir literaturas especializadas, como o caso dos catálogos de bibliografias, as biografias de autores da época, tanto de obras cristãs como "profanas" 4 .

As fontes de informação explicitam uma informação, independentemente de seu formato ou canal de comunicação, que pode ser, quanto ao formato: primária, secundária ou terciária; quanto ao canal de comunicação: formal, informal ou semiformal (HORLAND; ANDERSEN; SØNDERGAARD, 2005).

Está sempre atrelada a finalidade à que se destina, seu formato pode ser variado, artigos científicos, relatórios, periódico, banco de dados, noticiosos, depende da especialidade de cada segmento para o qual ela se propõe. Sugahara e Jannuzzi (2005, p. 47) enfatizam que as “[...] atividades realizadas para a aquisição de licenças, patentes e know-how realizada por universidades e institutos de pesquisa e empresas de consultoria são denominadas fontes especializadas".

Independentemente de seu formato ou canal de comunicação, uma informação especializada é uma fonte útil e necessária, seja para quem for, principalmente as estruturadas/ organizadas, com o exacerbado aumento de informação, especialmente as que estão disponíveis na internet, se faz necessário conhecer e filtrar informações para que se possa utilizar fontes confiáveis.

Há uma crescente demanda de organização e uso de informação especializada, devido a diversidade informacional coexistente na sociedade. Para Borges (2007) esses serviços

4 Obras profanas, consideradas contrarias aos dogmas cristão, estudos de física, medicina e astronomia Conforme Martins (2002) os pesquisadores da época eram perseguidos e punidos como hereges por não seguirem aos ensinamentos cristãos. são de suma importância para a sociedade, da gestão, organização e aplicação da informação especializada para o efetivo uso. E quanto maior for o grau de exigência dos usuários, mais específica será a informação contida em sistemas informacionais especializados.

As contribuições do acesso aberto são evidentes e pertinentes para o crescimento da ciência e sociedade, com a ajuda de redes especializadas, repositórios, bases de dados, portais, blogs, metabuscadores e blogs - páginas pessoais, é possível propagar o acesso ao conhecimento científico.

No Brasil o movimento do acesso aberto alavancou diversos serviços informacionais que vem se fortalecendo cada vez mais, cita-se como exemplo o SciELO, BINAGRI, os Repositórios institucionais e temáticos, entre outros. As fontes informacionais especializadas, disponíveis na internet e em canais de comunicação formal, como periódicos científicos, deram espaço para a propagação de matérias de acesso aberto, no qual o altruísmo é o que movimenta boa parte desses acervos, já que muitas plataformas são criadas e mantidas por pessoas que são adequas à causa, esse é o fator impactante para o sucesso do acesso aberto, o trabalho e publicação voluntária de pessoas que objetivam a visibilidade e acesso do conhecimento, científico ou não.

\section{REDES INFORMACIONAIS}

As redes informacionais e a cooperação entre unidades de informação são práticas que começaram a ser aplicadas desde o séc. XX. Silva (1986) em seu estudo feito no Brasil, apresentou o uso de serviços informacionais por unidades de informação com base na prática de cooperação. Elkington e Massie (1999) indicam que a composição de redes de informação surgiu em 1916 nos EUA e Reino Unido. Tomaél (2005) enfatiza o uso de redes informacionais para a troca de informação, por meio da cooperação, iniciada em meados do século 20, e que vem crescendo constantemente.

De lá para cá, em pleno séc. XXI, os serviços de redes informacionais ficaram mais particularizados, atuam com informação especializada e campos distintos de conhecimento, devido a grande massa informacional nos diversos meios de 
comunicação, e no aprofundamento de cada área de estudo. Tomaél $(2005$, p. 22) salienta que, "a maioria delas [redes] se dedica aos serviços de indexação e resumos que produzem as bases de dados, mas há, também, redes que desenvolvem: empréstimo entre bibliotecas, comutação, bases cadastrais, instrumentos terminológicos, entre outros".

O processo de obtenção, tratamento e disponibilização da informação especializada por meio da cooperação possibilitou a geração de diversos serviços e produtos informacionais, derivados de um sistema que permite a constituição de cruzamentos, análise de dados, emissão de relatórios, resumos, métricas entre outros produtos. Para Cédon (2005, p. 22) a definição de rede é guiada por sua funcionalidade, " [...] as redes são utilizadas para cooperação, compartilhamento, intercâmbio e acesso remoto à informação, documentos ou recursos computacionais".

As redes foram e são criadas para atender as demandas informacionais de uma determinada área do conhecimento, constituída por vários participantes em um sistema de colaboração. Segundo Guinchat e Menou (1994, p. 340-341) elas podem ser: centralizadas, descentralizadas ou mistas; A sua especialização é definhada por: a) função da rede - serviços desenvolvidos; b) especialidade - disciplina; c) usuário dos serviços e produtos da rede.

A principal característica das redes informacionais, conforme Rozado (2004) é a intangibilidade, conta com a participação do usuário. Por sua particularidade oferecem vários tipos de serviços que são relacionados conforme suas características e funções:

- $\quad$ Toda rede ou serviço de informação busca atender as necessidades informacionais de seus usuários;

- Tem relação direta com o usuário e a informação;

- É uma atividade que visa a identificação, aquisição, processamento e disseminação da informação através de um serviço ou produto informacional.

É custoso e oneroso para uma organização criar uma base de dados informacional nova. Ao participar de uma rede ou sistema informacional esses custos são minimizados e as vantagens maximizadas, devido o acesso ao acervo gerado pelos cooperadores. Um exemplo desse tipo de rede é a BIREME, BINAGRE, BRAPCI, HBL, SciELO e SINAIS, são redes constituídas para atender à necessidade de estrutura informacional, por ser mais fácil encontrar uma informação em uma base já estruturada do que procurar informação em diversos canais, sem saber o que realmente é confiável.

Cedón (2005, p. 22) enfatiza que, os cooperados que participam de uma rede de informação têm o benefício do acesso de "variedades de recursos informacionais" socializados, assim como as instituições que mantém as redes, elas obtêm informação, racionalizam gastos com infraestrutura e acervo, e minimizam esforços, pois todos cooperam.

Ao participar de uma rede de informação os benefícios são visíveis, no entanto, em contrapartida, deve haver a troca de informação, todos os participantes alimentam a rede, para que seja possível constituir com o acervo do banco informacional. Cada rede se organiza de acordo com seu interesse, seja por temática ou área, para todas, o foco é a informação especializada, de alta credibilidade e atualizada.

\section{I Bibliotecas digital}

Para apresentar os exemplos de aplicação de biblioteca digital, usamos as definições dos autores, Norte (2010), Campello e Caldeiro (2008), Cunha e Cavalcanti (2008). São aplicadas essas definições para aquelas que se auto denominam como biblioteca digital e eletrônica, entendendo que ambas têm a mesma função.

De acordo com Norte (2010, p. 18) biblioteca digital é aquela "que tem como base informacional conteúdos em texto completo em formatos digitais- livros, periódicos, teses, imagens, vídeos e outros - que estão armazenados e disponíveis para acesso".

Campello e Caldeira (2008, p.118) as define como, "[...] seria aquela que teria, além de seu catálogo, também os textos dos documentos de seu acervo, armazenados de forma digital, permitindo sua leitura na tela do monitor ou sua importação (download) para o disco rígido do computador que funcionasse como porta de acesso à Internet".

Cunha e Cavalcanti (2008, p.50) indicam no dicionário de terminologia da área que a 
biblioteca digital visa proporciona o "acesso em linha, não somente a catálogos, mas também a uma grande variedade de recursos eletrônicos existentes na própria biblioteca ou fora".

$\mathrm{O}$ primeiro exemplo e a Scientific Electronic Library Online-SciELO ${ }^{5}$, especializada em publicações periódicas; lançada em 1998, por meio da cooperação entre a Fundação de Amparo à Pesquisa do Estado de São Paulo - FAPESP, o Centro Latino Americano e do Caribe de Informação em Ciências da Saúde (BIREME/OPAS/OMS) vinculada ao programa da UNESCO, mais tarde fez parceria com o Conselho Nacional de Desenvolvimento Científico e Tecnológico - CNPq, com o intuito de propagar ciência de qualidade e de acesso aberto, promovendo a indexação, agregação, publicação e interoperabilidade dos acervos que o compõe, tem mais de um milhão de acesso por dia (PACKER, 2014).

A rede tinha como ambição propagar a ciência nos países da América do Sul, mas logo se tornou intercontinental e ibero-Americana e da África do Sul, nos moldes do acesso aberto de forma interrupta, agregando cada vez mais periódicos de acesso aberto ao acervo (PACKER, 2014, p. 15). No SciELO ${ }^{6}$ algumas áreas publicam mais de acesso aberto do que outras:

- $\quad$ Ciências da Saúde (444 periódicos)

- $\quad$ Ciências Humanas (406 periódicos)

- Ciências Sociais Aplicadas (349 periódicos)

- $\quad$ Ciências Biológicas (162 periódicos)

- $\quad$ Ciências Agrárias (136 periódicos)

- $\quad$ Engenharia (110 periódicos)

- Ciências exatas e da terra (104 periódicos)

- $\quad$ Linguística, Letras e Artes (70 periódicos)

Este cenário mostra que as áreas com maior atuação e produção de acesso aberto são as da saúde, humanas e sociais aplicadas, talvez por compor o acervo de uma rede que tem o cunho científico/social, devido a sua vinculação aos órgãos internacionais e humanitários, com enfoque maior nestas áreas e ainda menor em outras, ou por ter uma necessidade mais emergencial. O plano de trabalho da UNESCO

5 Poderia ser considerada como base de dados de referências e textos integrais, mas aqui, apresentamos como se autodenomina.

6 Veja a lista completa no portal do SciELO. 20I8. em: <http://www.scielo.org/applications/scielo-org/php/ secondLevel.php? xmI=secondLevelForSubjectBy Letter\&xsl=secondLevelForSubjectByLetter $>$ de 2012-2019, de acordo com Packer (2017, p.13), prevê ações para alcançar alguns objetivos de curto, médio e longo prazo:

(i) Provisão de assessoria política em altas esferas e a construção de parcerias;

(ii) Fortalecimento das capacidades de adoção do AA (Acesso Aberto);

(iii) Servir como um centro de intercambio e informar o debate global sobre AA.

O SciELO por ser uma rede de comunicação científica formal de acesso aberto, no qual, seleciona, organiza e propaga os conteúdos especializados de diversas áreas do conhecimento, vem colaborando para o desenvolvimento científico social, em nível global. Em 2018 completa vinte anos de atividade ininterrupta, mantendo o foco na promoção e difusão do desenvolvimento científico em acesso aberto.

A biblioteca digital da ONU $(2017)^{7}$ tem aproximadamente novecentos mil registros de acesso aberto, com o intuito de promover amplo acesso e preservação da memória do conhecimento produzido e organizado pela ONU, sua plataforma utiliza códigos abertos, assim como há métricas para analisar o uso e visualização dos materiais disponíveis nela.

A UNESCO $(2017)^{8}$ junto a outras trinta e duas instituições parceiras lançaram em 2009 a Biblioteca Digital Mundial (World Digital Library), com materiais de bibliotecas e arquivos de todo o mundo de acesso aberto. Inclui: manuscritos, mapas, obras raras, filmes, áudios, impressos e fotografias.

Tem o movimento como a Biblioteca Comum (2017) ${ }^{9}$ do instituto Intersaber e do Baixa Cultura, é uma biblioteca digital que disponibiliza materiais de acesso livre, como: texto, áudio e vídeo como livros, revistas, fanzines, artigos, teses e dissertações, entrevistas, quadrinhos e filmes relacionados à Agricultura Urbana, Bens Comuns, Ciência Cidadã, Cultura Livre, Economia Colaborativa, Educação

\footnotetext{
7 Ver - ONU. Biblioteca Digital. 2017. Disponível em: <https:// digitallibrary.un.org/> e < https://nacoesunidas.org/onu-lanca-bibliotecadigital-com-900-mil-documentos-a-disposicao-do-publico/>

8 UNESCO. Biblioteca Digital do Mundo. 2017. Disponível em: <https://www.wdl.org/pt/> e < http://www.unesco.org/new/pt/brasilia/ communication-and-information/access-to-knowledge/libraries-andarchives/>

9 Ver mais em: BIBLIOTECADOCOMUM. Sobre. 2017. Disponível em: $<$ http://bibliotecadocomum.org/sobre>
} 
Expandida, Participação Digital, Tecnologias Sociais.

Biblioteca Digital da Biblioteca Nacional do Brasil, com acervo de 1.504.359 documentos de acesso aberto: artigos, exposições, acervo digital, hemeroteca digital, todo acervo é de domínio público. É parceira das Bibliotecas Digitais do Mundo, assim como o exemplo de outras bibliotecas ${ }^{10}$

Irlanda - National Library of Ireland: http:// www.nli.ie/en/intro/digital-library-printedresources.aspx

Hungria - Hungarian Electronic Library: http:/ / mek.oszk.hu/indexeng.phtml

Havaí - Ulukau - The Hawaiian Electronic Library: $\quad$ http://ulukau.org/index. $\mathrm{php} ? \mathrm{a}=\mathrm{p} \& \mathrm{p}=$ browse $\& \mathrm{wp}=\& \mathrm{cl}=2.3 .1 \& \mathrm{l}=$ haw

França - Gallica: http:/ / gallica.bnf.fr/

EUA - Library os Congress: http:/ / www.loc.gov/

EUA - Digital Public Library os America: http:// dp.la/

Espanha - Biblioteca Nacional de España: http:/ / www. bne.es/esp/catalogos/coleccionesdigitales.htm

Escócia - National Library os Scotland Digital Gallery: http://digital.nls.uk/gallery.cfm

Coréia do Sul - National Digital Library: http:// www.dlibrary.go.kr/

Austrália - Pandora: http:/ / pandora.nla.gov.au/

Comunidade Andina - Biblioteca Digital Andina: http://www.comunidadandina.org/bda/ default.aspx

Biblioteca digital do Patrimônio Iberoamericano: http:/ / www.iberoamericadigital.net/BDPI/

Biblioteca Digital Mundial: http://www.wdl. org/pt/

Digital Library Federation: http:/ / www.diglib.org/

Europa - The European Library: http://www. theeuropeanlibrary.org/tel4/

China - National Digital Library of China: http:// www.nlc.gov.cn/old/ndlc/index.htm

10 BN. 2018. Disponível em:< https://bndigital.bn.gov.br/bibliotecasdigitais-pelo-mundo/>
PLoS - Public Library of Science ${ }^{11}$, desde 2001 publica materiais científicos sem fins lucrativos, todos de acesso aberto, em várias áreas do conhecimento. Não é apenas acesso livre e irrestrito à pesquisa, é também sobre dados abertos, transparência na revisão pelos pares e uma abordagem aberta para a avaliação científica. Tem mais de 27.000 artigos publicados, 12 milhões de visualizações por mês, $2.000,000$ de downloads de artigos. Cerca de 7.000 editores e 78.000 revisores. Soma 300.000 visualizações na página do Twitter. Já publicou artigos de 61 prêmio Nobel Laureates. Permite acesso irrestrito ao acervo.

SPELL-Scientific Periodicals Electronic Library ${ }^{12}$, é uma biblioteca de artigos científicos, de acesso gratuito à informação técnicocientífica. Tem em seu acervo 42.745 documentos, contabiliza 12.372.461 downloads e 39.324.364 acessos.

BDTD - Biblioteca Digital de Teses e Dissertações ${ }^{13}$, gerenciada pelo Instituto Brasileiro de Informação em Ciência e Tecnologia - IBICT, disponibiliza teses e dissertações produzidas nas Instituições de Ensino Superior em nível nacional, dentre outras bases de dados referenciais ou de fontes.

Ambos exemplos mostram a força do movimento do acesso aberto em bibliotecas digitais e a importância imensurável desses serviços para toda a sociedade, científica ou não.

\subsection{Base de dados}

Para Rowley (2002, p.106) base de dados, simploriamente, "são o modo como os dados são armazenados em computadores". A autora, apresenta dois tipos de bases de dados, as de referências: "remetem ou encaminham o usuário a outra fonte, como um documento, uma pessoa jurídica ou pessoa física, para que obtenha informações adicionais, ou texto completo de um documento" (ROWLEY, 2002, p.109-110); e as bases de fontes, que, "contêm os dados originais e constituem um tipo de documento eletrônico" (ROWLEY, 2002, p.110).

\footnotetext{
II PLoS. 2018. Disponível em:<https://www.plos.org/> e <https://www. plos.org/annual-update>

12 SPELL. 2018. Disponível em: <http://www.spell.org.br/>

13 BDTD, organiza, representa e remete à página de origem do texto. 2018. Disponível em: <http://bdtd.ibict.br/vufind/>
} 
Cunha (2016, p.57) enfatiza que, "Base de dados é a expressão utilizada para indicar a coleção de dados que serve de suporte a um sistema de recuperação de informações".

Para Cunha e Cavalcanti (2008, p. 43) base de dados são “2. b) [...] serviços básicos de acesso, interrogação, apresentação dos resultados [...]. 3. Coleção de dados inter-relacionados, armazenados juntos, com redundância controlada para servir a uma ou mais aplicações".

Observando as definições, identificouse várias bases de dados disponíveis, sejam em ambientes organizacionais ou instituições de pesquisas, servem como fonte de informação especializada, conforme a necessidade do usuário. Assim, uma base de dados contém informações que são capturadas em diversas outras fontes de informação, ou mantém repositórios de documentos e/ou arquivos gerados eletronicamente, ou processados em meio magnético (digitalizados).

Em nível internacional podemos apresentar a plataforma SciCrunch Americana, dentre as diversas bases de dados existentes, ela permite o "compartilhamento e exibição de dados. [...] atualiza os dados automaticamente para todos os portais semanalmente. As comunidades de usuários também podem adicionar seus próprios dados, no entanto, este não é atualmente um serviço gratuito" (SCICRUNCH, 2018, Tradução nossa) $)^{14}$.

Open Grey ${ }^{15}$ - Base de literatura cinzenta (teses, dissertações, relatórios técnicos, etc.) da Europa. Disponibiliza o acesso aberto a 700.000 documentos de diversas áreas do conhecimento.

No Brasil temos o Centro LatinoAmericano e do Caribe de Informação em Ciências da Saúde, conhecido como BIREME ${ }^{16}$, permitindo o armazenamento de informações sobre pesquisas, publicações e relatórios de pesquisa na área da saúde.

Literatura Digital ${ }^{17}$ - contém 76.263 obras, 19.201 autores cadastrados e 5.697 arquivos digitalizados, fornece acesso gratuito a textos literários em versão integral na internet, obras brasileira e portuguesa.

\footnotetext{
14 SciCrunch. 2018. Disponível em:< https://scicrunch.org/> Acesso em: 29 jan. 2018

I5 Open Grey. 2018. Disponível em: <http://www.opengrey.eu/>

16 BIREME. 2018. Disponível em: <http://bvsalud.org/>

17 LITERATURA DIGITAL. 2018. Disponível em: <https://www. literaturabrasileira.ufsc.br/>
}

A Base de Dados em Ciência da Informação - BRAPCI ${ }^{18}$ agrega títulos e artigos de periódicos na área da Ciência da Informação, permite aos pesquisadores da área manter-se atualizados sobre as temáticas publicadas nos periódicos brasileiros da área. Disponibiliza informação a respeito das instituições na qual os periódicos são vinculados, periodicidade, métricas de acesso e visualização dos materiais. Serve como espaço para a preservação dos artigos de periódicos que deixam de existir, mas seu acervo continua disponível via BRAPCI.

BASE - Bielefeld Academic Search Engine ${ }^{19}$, base alemã, fornece acesso aberto a mais de 100 milhões de documentos de 5.000 fontes, disponíveis em diversas línguas, artigos, livros, teses, relatórios, os mais variados tipos de documentos, todos de open access.

LIVIVO - Leibniz Information Centre for Life Sciences, da Alemanha ${ }^{20}$, é especializada na área da saúde, medicina, nutrição, meio ambiente e agricultura. Disponibiliza mais de 55 milhões documentos de 45 bases especializadas. Todo seu acervo é de acesso aberto.

Dulcinea $(2018)^{21}$, criada em 2008, a base indexa materiais oriundos de repositórios, periódicos e de outras bases base de publicação científica, distinguindo o que é de acesso aberto e não é por etiquetagem de cor, apesar de visar as publicações de open access, muitos parceiros disponibilizam para indexação seus acervos mistos, os quais a base separa por meio da etiquetagem.

Dada as características de uma base de dados, a diversidade e dinamismo desse meio como forma de armazenamento de informações vem sendo utilizado por diversas instituições, são organismos importantes quando se trata do acesso ao acervo científico ou especializado.

\subsection{Diretórios}

Para Cunha e Cavalcanti (2008, p.127) um diretório "3. d. organiza os domínios numa hierarquia, especificando o relacionamento entre todos os domínios da árvore". Pode ser

\footnotetext{
I8 BRAPCl. 2018. Disponível em: <http://www.brapci.inf.br/>

19 BASE- Bielefeld Academic Search Engine.2018. Disponível em: <https:// www.base-search.net/about/en/>

20 LIVIVO. 2018. Disponível em: <https://www.livivo.de/app>

21 Dulcinea. Sobre. 2018. Disponível em: <https://www.accesoabierto. net/dulcinea/>
} 
comercial, de fornecedor, de uma área específica ou temático, concentra um único domínio destinado a atender ao seu objetivo ou objeto. São variados os tipos de diretórios que existem, aplicados em diversas finalidades, como ex. diretório acadêmico de biblioteconomia, é específico de uma área porque é somente da biblioteconomia. Existe uma gama grande de diretórios na internet, é um recurso bastante difundido.

O Diretório de Recursos Acadêmicos de Acesso Aberto - ROAD foi lançado em 2013, atua por meio do Centro Internacional ISSN e do Setor de Comunicação e Informação da UNESCO, que visa registrar as publicações de: revistas, conferências e repositórios acadêmicos. Fornece acesso a 1,8 milhões registros bibliográficos de acesso aberto. O ROAD tem os seguintes propósitos:

i. Fornecer em um único ponto de acesso a diferentes tipos de recursos acadêmicos on-line publicados em todo o mundo e disponíveis gratuitamente;

ii. Fornece informações sobre a qualidade e a proeminência dos recursos de acesso aberto, ou, os critérios que eles atendem, indicando por quais serviços ou indicadores de jornais estão cobertos;

iii. A cobertura do ROAD foi desenvolvida para dar uma visão geral da produção acadêmica de acesso aberto em todo o mundo (para fins de estatística, por exemplo);

iv. Demonstrar novas formas de usar o ISSN para compilar informações de várias fontes.

Sendo assim, o diretório compila listagens das áreas de publicação em cinco regiões intercontinental, África (305), Estados Árabes (689), Ásia e Pacífico $(7,646)$, Europa e América do Norte $(11,804)$, América Latina e Caribe $(2,598)$, e, Mundo com $(23,252)$ registros. ${ }^{22}$

$\mathrm{Na}$ divisão por país, o Brasil no ROAD $(2018)^{23}$, consta com 1,415 registros, nas seguintes áreas:

- Ciências sociais, economia, política (526)

- $\quad$ Ciências aplicadas, tecnologia (243)

22 Ver mais em ROAD. Publicações de Acesso Aberto. 2017. Disponível em: <http://road.issn.org/en/statistics>

23 Ver mais ROAD. Acesso Aberto no Brasil. 2017. Disponível em: < http://road.issn.org/en/statistics >
- $\quad$ Artes e humanidades (228)

- Ciências médicas (227)

- $\quad$ Ciências puras e matemática (95)

- Informação, mídia, bibliotecas (50)

- Multidisciplinar (46)

Cabe ressaltar que o ROAD relaciona as publicações que tenham registros de ISSN denominados de acesso aberto e que estão indexados em: EconLit, PsycINFO®, Scopus, Latindex, DOAJ, O Registro dos Guardiões, SJR, SNIP, Índice Católico de Periódicos e Literaturas ATLAS ${ }^{\circledR}$, ATLAS Religion Database ${ }^{\circledR}$, Resumo do CAB, GeoRef, Saúde global, Resumos de Linguística, MEDLINE®, PubMed Central® (PMC), dados disponíveis em maio de 2018 (ROAD, 2018).

DOAB - Diretório de Livros de Acesso Aberto $^{24}$, disponibiliza 10.857 livros e capítulos de livros acadêmicos, com acesso irrestrito ao acervo de 255 editoras.

O JURN directory $(2017)^{25}$ também é um diretório de revistas de acesso aberto, com cobertura em todas as áreas do conhecimento, com cerca de quatro mil periódicos na área de artes e humanidades, todas de língua inglesa. O OpenECO, também da Jurn $(2017)^{26}$ é um diretório de revistas na área de ecologia e naturezas, disponibiliza cerca de oitocentos periódicos de acesso aberto.

EUMED.NET ${ }^{27}$ : é um diretório de materiais de acesso aberto: Dicionários, livros eletrônicos, periódicos, teses, vídeos e apresentações. Tem mais de 20 anos de atuação, sua coleção comtempla mais de 1.600 livros, 200 teses e 19 revistas acadêmicas. Organizou mais de 150 congressos virtuais.

Open $D O A R^{28}$ é um diretório de repositórios acadêmicos de acesso aberto. A iniciativa surgiu com o movimento de acesso aberto em meados de 2003, mobilizando a equipe para captar, organizar e disponibilizar em acesso aberto 3.520 diretórios de acesso aberto ativos e disponíveis, de vários continentes e países.

Os diretórios são ferramentas úteis ao que tange fontes de informação especializadas,

\footnotetext{
24 DOAB. 20I8. Disponível em: <https://www.doabooks.org/>

25 JURN. Diretory. 2017. Disponível em: <http://www.jurn.org/ directory/>

26 JURN. Open ECO. 2017. Disponível em: <https://jurnsearch. wordpress.com/titles-indexed-ecology-related/>

27 EUMED.NET. 2018. Disponível em: <https://eumed.net/>

28 OpenDOAR. 2018. Disponível em: <http://www.opendoar.org/index. html>
} 
organizam coleções de diferentes tipologias e formatos em um único local e de diversas áreas do conhecimento, por ser de acesso aberto, facilita o acesso e a obtenção da informação para qual interessado.

\subsection{Portais}

Conforme o dicionário de biblioteconomia e arquivologia, portal representa uma "[...] porta de entrada para navegação. Em geral inclui vários tipos de recursos, tais como: correio eletrônico, fóruns de discussão, mecanismo de busca e lojas de comércio eletrônico" (CUNHA; CAVALCANTI, 2008, p.287).

O Portal de Acesso Aberto Global - GOAP é financiado pelos Governos da Colômbia, Dinamarca, Noruega e do Departamento de Estado dos Estados Unidos, disponibiliza informações científicas de 158 países, mostra o status de cada país no ranking, assim como a visão global do cenário do acesso aberto. O portal GOAP (2017) ${ }^{29}$ oferece os seguintes recursos:

(i) Conhecimento filtrado de cada país sobre o status do acesso aberto;

(ii) Principais organizações envolvidas no acesso aberto nos estados membros;

(iii) Áreas temáticas de acesso aberto;

(iv) Publicações importantes e postagens de blog sobre acesso aberto de diferentes regiões do mundo;

(v) Avaliação crítica das principais barreiras ao acesso aberto em cada país;

(vi) Potencial de acesso aberto nos estados membros da UNESCO;

(vii) Mandatos de financiamento e depósito;

(viii) Links para iniciativas de Acesso aberto no mundo.

Segundo o GOAP (2017), o Brasil é o país mais ativo do continente, publica certa de 2,7\% dos trabalhos científicos mundiais e $97 \%$ de suas revistas são de acesso aberto, esse movimento tende a crescer cada vez mais.

O portal do acesso aberto da $U_{S P}{ }^{30}$ reúne e disponibiliza fontes e materiais, desde sugestão

29 Veja mais no portal do GOAP. Sobre. 2017. Disponível em: < http:// www.unesco.org/new/en/communication-and-information/portals-andplatforms/goap/>

30 Ver em USP. Acesso aberto. 2017. Disponível em: <http://www. acessoaberto.usp.br/> de portais, repositórios, páginas, serviços, bibliotecas digitais, notícias e documentários a respeito do assunto.

Portal do Domínio Público ${ }^{31}$, é um portal brasileiro, criado em 2004, detém conteúdos variados: áudios, vídeos, livros, documentos, imagens, textos, todos de domínio público, sem qualquer restrição de acesso e uso do acervo.

Accesoabierto.net ${ }^{32}$ é um portal espanhol direcionado a autores e grupos de pesquisa que necessitam de informação de acesso aberto. Dispõe de documentos dos grupos de pesquisa, discussões e comentários postados no blog do portal, orientações e informações sobre publicação científica.

The Public Domain Review ${ }^{33}$ - fundado em 2011, tem o foco nas obras que já caíram em domínio público, fora de copyright, compartilhar e construir sem restrição. O objetivo é promover e celebrar o domínio público em sua abundância e variedade. Nele, encontram-se, imagens, livros, filmes, áudio, textos de todos os gêneros e coleções, etc.

LivRe $^{34}$ - desenvolvido pela Comissão Nacional de Energia Nuclear (CNEN) e o Centro de Informações Nucleares (CIN) brasileiras. Contém 7.270 títulos de periódicos de acesso aberto em várias áreas do conhecimento, todo acervo está disponível para consulta na internet.

Outra iniciativa é o eduCAPES $(2017)^{35}$ um portal que disponibiliza objetos educacionais abertos "textos, livros didáticos, artigos de pesquisa, teses, dissertações, videoaulas, áudios, imagens e quaisquer outros materiais de pesquisa e ensino que estejam licenciados de maneira aberta, publicados com autorização expressa do autor ou ainda que estejam sob domínio público".

Portal Catarina ${ }^{36}$ : dispõe de obras literárias catarinenses, desde o séc. XIX, com acesso irrestrito ao acervo de 4.521documentos

\footnotetext{
3I PORTAL DO DOMÍNIO PÚBLICO. 2018. Disponível em: <http:// www.dominiopublico.gov.br/pesquisa/PesquisaObraForm.jsp $>$

32 Accesoabierto.net. Sobre. 2018. Disponível em: < https://www. accesoabierto.net/>

33 The Public Domain Review. Sobre 2018. Disponível em: <http:// publicdomainreview.org/>

34 LivRe. 2018. Disponível em: <http://www.cnen.gov.br/centro-deinformacoes-nucleares/livre>

35 Ver mais em: EDUCAPES. Sobre. 2017. Disponível em: <https:// educapes.capes.gov.br/redirect?action $=$ about $>$

36 Portal Catarina. 2018. Disponível em: <https://www.portalcatarina.ufsc. $\mathrm{br} />$
} 
de 332 autores e 2.652 arquivos que foram digitalizados.

Associação de editores acadêmicos de acesso aberto - OASPA $^{37}$, criado em 2008, apresenta informações sobre a associação, conferências da área, filiação, eventos de acesso aberto, seu blog e contatos, além de publicações a respeito do assunto.

O foco desses portais destina-se em publicar fontes ou informações a respeito do acesso aberto ou que as fontes são de caráter de acesso aberto, na maioria delas especializadas e científicas em alguma área ou instituição de pesquisa ou conhecimento.

\subsection{Repositórios}

Os repositórios são usados para armazenar, organizar e preservar acervos de memória ou de interesse público e disseminar a informação. Repositórios são estruturas hierarquizadas para facilitar a recuperação dos dados, por isso são encontrados repositório temáticos, institucionais, de periódicos, teses, pesquisas e dados, são inúmeras aplicações. Cunha e Cavalcante (2008, p.322) os classificam como, "1. coleção, digital ou em papel, que capta e preserva a memória intelectual de uma comunidade ou organização; memória institucional."

No Brasil, há diversas iniciativas com relação aos repositórios digitais em universidades, implantadas ou em fase de implantação em instituições acadêmicas, por exemplo: Repositório Institucional Digital do IBICT (RIDI), Repositório da Universidade de Brasília (UnB) e o Repositório da Universidade Estadual de Campinas (UNICAMP).

Costa e Silva (2008, p.145 - 149) afirmam que as "fontes de informação que já são estruturadas no meio digital têm especificidades que favorecem a leitura não linear e a convergência de várias mídias". Nesse sentido as autoras discutem o que vem a ser os repositórios institucionais caracterizando-os em sentido amplo e estrito. "No sentido estrito, repositórios de informação são aqueles que participam do movimento de arquivos abertos e operam de acordo com os protocolos estabelecidos nas convenções de OAI".

37 Acesse o portal, Open Access Scholarly Publishers Association. 2018. Disponível em: <https://oaspa.org>
Camargo e Vidotti (2009) ressaltam que nos últimos anos os repositórios institucionais são alvos da atenção por parte de universidades e bibliotecas universitárias, pois estão inseridos no movimento do Open Access Initiative, que tem por objetivo a promoção do acesso livre e irrestrito à literatura científica e acadêmica. Impactando diretamente no trabalho desenvolvido pelos investigadores e instituições, contribui para a reforma do sistema de comunicação científica, reassumindo o controle acadêmico sobre a publicação, aumentando a competição e reduzindo o monopólio das revistas científicas e editoras comerciais.

A realizada pelos autores Murakami e Fausto (2013, p.188) teve como objetivo o "levantamento dos repositórios institucionais de Instituições de Ensino Superior (IES) no Brasil com o intuito de analisar quantitativa e qualitativamente o panorama nacional, testando a eficácia de uma nova ferramenta de análise e visualização de dados livremente disponível online", os autores chegaram a um número considerável, 49 até agosto de 2013.

Desses repositórios, 65.3 \% são federais (32 repositórios), $18.4 \%$ são particulares (9 repositórios), $14.3 \%$ são estaduais (7 repositórios) e $2 \%$ são municipais (1 repositório). Percebese que as instituições federais detêm o maior número de repositórios a época, demonstrando com isso a produção de seus pesquisadores.

O ROAR ${ }^{38}$ realiza o registro de repositórios de acesso aberto, de qualquer país. Ao pesquisar por Brasil recupera-se 166 repositórios cadastrados no ROAR.

ARCA - Repositório Institucional da Fiocruz ${ }^{39}$, lançado em 2011, provem o acesso gratuito ao acervo: anais de congresso, artigos, capítulo e livros, cartas, dissertações e teses, fotografias, jogos, manuais técnicos, patentes, recursos educacionais, relatórios, boletins e vídeos. Registra em seu sistema 19,426 documentos, dos quais, obteve 496,503.8 downloads e 423,265 visualizações.

LUME - Repositório Digital da Universidade Federal do Rio Grande do Sul ${ }^{40}$, criado em 2007. Visa reunir, preservar, divulgar e garantir o acesso a 23,376 documentos disponível em seu acervo.

\footnotetext{
38 ROAR. Sobre. 2018. Disponível em: <http://roar.eprints.org>

39 ARCA. Sobre. 2018. Disponível em: <https://www.arca.fiocruz.br/>

40 LUME. Sobre. 2018. Disponível em: <http://www.lume.ufrgs.br/>
} 
PORTCOM $^{41}$, repositório brasileiro de livre acesso à produção em ciências da comunicação. Criado em 1981. Nele encontra-se, textos, artigos apresentados em congressos, livros, capítulos de livros, e-books e revistas científicas publicadas pela entidade, ao todo são 22.996 documentos.

O Arxiv.org (2017) ${ }^{42}$ é um repositório temático de acesso aberto, criado em 1991, disponibiliza materiais nos seguintes temas: física, matemática, ciência da computação, ciências não-lineares, biologia quantitativa, finanças quantitativas e estatísticas. É administrado pela biblioteca da Universidades de Universidade de Cornell, NY.

O PubMed ${ }^{43}$, um repositório temático na área Biomédica, mantendo uma "ferramenta para publicação eletrônica de revistas, também possui mecanismos para inclusão de arquivos avulsos" (FERREIRA, 2007, p.160).

Dissemin $^{44}$, lançado em 2015 é mantido pela CAPSH - associação francesa sem fins lucrativos que promove o acesso aberto a publicações acadêmicas. Indica ter 25 megabits de dados de acesso aberto.

Os repositórios surgem como uma opção para armazenar coleções de diversos tipos de materiais em um mesmo local, usa de estrutura e software livre, predefine política de arquivamento, indexação, acesso e direitos autorais dos materiais disponíveis. Amplamente utilizados para a preservação de acervos digitais, sejam temáticos, institucionais ou de áreas do conhecimento.

\subsection{Metabuscadores}

São mecanismos especializados em fazer buscas simultâneas de um determinado termo em vários outros sistemas de buscas ou de armazenagem de dados. Os comuns buscam o termo em buscadores gerais, recuperando tudo que possa estar relacionado ao termo, documentos, propagandas e lixos. Existe também os metabuscadores especializados em áreas do conhecimento, buscam tanto em mecanismos especializados como gerais, mas que, na maioria

\footnotetext{
41 PORTCOM. Sobre. 2018. Disponível em: <http://www.portcom. intercom.org.br/>

42 Ver mais em: ARXIV. Sobre. 20I7. Disponível em: < arXiv.org>

43 PUBMED. Sobre. Disponível em: <https://www.ncbi.nlm.nih.gov/ pubmed/?cmd = HistorySearch\%26querykey $=8>$

44 DISSEMIN. Sobre. Disponível em: <https://dissem.in/>
}

não são direcionados para fontes de acesso aberto.

Para Cunha e Cavalcante (2008, p.246) é um sistema de busca que tem a "utilização da mesma estratégia de busca em diversos computadores ou sistemas informatizados para encontrar itens que estejam dispersos em coleções distribuídas; as diversas respostas recebidas são fundidas pelo sistema e o resultado é apresentado para o solicitante numa forma integrada e consistente". Os metabuscadores acadêmicos são usados para recuperar em diversos serviços informacionais acadêmicos ao mesmo tempo, por exemplo várias bases de dados, repositórios, periódicos e portais, etc.

Outro movimento que visa disseminar as publicações de acesso aberto no Brasil é o Oasisbr $(2017)^{45}$, mecanismo de busca multidisciplinar de publicações científicas de acesso aberto, materiais, autores, universidades e instituições Brasileiras e Portuguesas. Os dados são coletados na biblioteca digital de teses e dissertações BDTD e Repositório Científico de Acesso Aberto de Portugal - RCAAP $^{46}$. Que recentemente coletaram dados de 384 redes, obtiveram $1.915,752$ registros, todos de acesso aberto.

JURN foi fundado em 2009 é mantido por David Hade, britânico da universidade e cidade de Birmingham, "passou sete anos" construindo a ferramenta, ${ }^{16}$ com o intuito de disponibilizar o conhecimento científico acessível a todos. JURN tem várias ferramentas que atuam no open access, usa um mecanismo simples de busca, os sistemas de refinamentos estão embutidos e os resultados são presentados em lista, o usuário pode visualizar os documentos por data de publicação. É uma organização sem fins lucrativos, não tem vínculo com empresas ou instituições comerciais. recupera materiais de todas as áreas do conhecimento e que sejam totalmente de acesso aberto. ${ }^{47}$

GRAFT é um metabuscador do Jurn $(2017)^{48}$, recupera matérias de acesso aberto em repositórios acadêmicos do mundo, tem em seus registros 4.482 repositórios de open access.

\footnotetext{
45 Ver mais em: OASISBR. Sobre. 20I7. Disponível em: <http://oasisbr. ibict.br/vufind/Contents/Home?section = networks $>$

46 RCAAP - Ver mais em: <https://www.rcaap.pt/>

47 Ver mais em: JURN. Sobre. 2017. Disponível em: <http://www.jurn. org/\#gsc.tab=0> e <https://jurnsearch.wordpress.com/about/\#use >

48 GRAFT. Buscador de repositórios acadêmicos. 2017. Disponível em: <http://www.jurn.org/graft/index.html>
} 
Buscador de projetos da Jurn $(2017)^{49}$, visa recuperar projetos que almejam financiamento em doze instituições: Kickstarter, Go Fund Me, Patrocínio, Peerbackers, Meus Sherpas, Fundar, Nós fizemos isso, CrowdCube, CoFundos, IndieGoGo, RocketHub, Patreon. Material de acesso irrestrito.

CORE $^{50}$, desenvolvido em 2011, pesquisa e recupera publicações de acesso aberto em repositórios, bibliotecas digitais, em portais e periódicos. Indica em sua página que recupera em torno de 126.741.126 artigos de acesso aberto.

Open Access Button For Libraries ${ }^{51}$, o sistema britânico foi lançado em 2013, recupera publicações de acesso aberto em vários sistemas, base de dados, repositórios, periódicos. Disponibiliza a função button para que o usuário tenha mais comodidade ao fazer sua busca de matérias de open access.

Esses sistemas de busca são especializados em recuperar materiais acadêmicos em estruturas informacionais que seja integral ou parcialmente de open access. São sistemas facilitadores do acesso ao objeto ou informação, principalmente as que estão em acesso aberto.

\subsection{Blogs}

“Os blogs são parte de uma crescente conjunção de comunicação pessoal e ferramentas de gerenciamento de informação, fornecem um mar infinito de histórias e links" (ARAÚJO, 2010, p.201). Tomando essa afirmação como verdadeira os Blogs são meios que permitem a troca de informação em meio eletrônico sobre diversos assuntos, permitindo interagir com públicos específicos, no entanto, deixou de ser apenas pessoal e passou a ser, também, institucional.

A internet proporcionou o desenvolvimento de estratégias de comunicação por meio de elementos textuais, visuais e orais, utilizando o computador como veículo de acesso a esses materiais. Nesse sentido, os Blogs permitem a elaboração de textos sobre determinado assunto, assumindo o papel de manter os usuários atualizados sobre determinados assuntos. Os usuários, por sua vez, podem participar das discussões deixando suas impressões sobre os textos produzidos pelo gestor (es) dos Blogs (DI LUCCIO; COSTA, 2010)

O termo Blog surgiu em 1997, quando Barger utilizou "a palavra weblog" para referenciar sites que tinham como objetivo "divulgar links de novos outros sites que eram criados diariamente". A partir de então aqueles que criam Blogs, foram denominados de Blogueiros, sendo os responsáveis por alimentar esse novo formato de interação na internet (ALMADA, 2011).

\begin{abstract}
Se a tela do computador se tornou um suporte textual, podemos compreender que, ao interconectar as telas dos computadores mundiais, a internet gerou um suporte textual de dimensões planetárias. Qualquer pessoa que disponha de um computador e tenha acesso à internet passa a poder publicar qualquer tipo de texto sem restrições e sem interferências de escribas, tipógrafos, impressores, corretores ou editores. $\mathrm{Na}$ tela conectada à internet, o escritor se tornou livre para desenvolver todo o processo de confecção e de divulgação de um texto. Além disso, diferentemente do que acontecia na era do rolo, do códice e da imprensa, o escritor de hipertextos - os textos eletrônicos - pôde abandonar a clássica lógica linear e dedutiva e escrever textos que (por meio de links) permitem o deslocamento da leitura para outros textos (DI LUCCIO; COSTA, 20I0, p. 135)
\end{abstract}

Relacionando os Blogs e o acesso aberto, cita-se como modelo a página de Kuramoto ${ }^{52}$, o professor tem sido o defensor do movimento de Acesso Aberto, atuou no Instituto Brasileiro de Informação em Ciência e Tecnologia - IBICT, no período de 1983 a 2011 à frente de diversos projetos, a exemplo a plataforma SEER, publica grande parte de suas pesquisas em seu blog pessoal. Outros pesquisadores brasileiros a fazer ciência via blog são os professores, Aldo

\footnotetext{
49 JURN. Buscador de projetos. 2017. Disponível em: <http://www. jurn.org/project-search/index.html>

50 CORE. Sobre. 20I8. Disponível em: <https://core.ac.uk/about>

51 OPEN ACCESS BUTTON FOR LIBRARIES. Sobre. 2018. Disponível em: <https://openaccessbutton.org/>
}

52 KURAMOTO. Blog. 2018. Disponível em <https://kuramoto.
wordpress.com/> 
Barreto $^{53}$, Ronaldo Mota ${ }^{54}$, Célia Dias ${ }^{55}$, Ursula Blattmann ${ }^{56}$, entre outros.

SciELO em Perspectiva $^{57}$ publica informações científica de acesso aberto, com linguagem simples. Segundo o blog (2018) tem o objetivo de publicizar o conhecimento científico das coleções disponíveis para o acesso no SciELLO, com linguagem entendível a todos.

O Feedspot ${ }^{58}$ é um blog que lista vários outros blogs, disponibiliza informações a respeito do tema e instituição ou pessoa responsável. Separa por assunto, em ciência, apresenta 109 blogs, entre eles está: New York Times, The Guardian, Oxford Science, PLoS, Forbes Science, Cosmos Magazine, National Geographic New, Phy. org Chemistry, Space.com, Discover Magazine, entre outros. São ao todos, 38 modalidades e áreas. Categoriza a presença destes nas redes sociais e ranqueia os mais populares.

Blog PLoS ${ }^{59}$ - criado em 2009 para compartilhar e divulgar de forma rápida as ideias científicas, no qual autoridades em determinados assuntos escrevem de forma entendível a todos sobre o tema, popularizando o conhecimento científico, em diversas áreas do conhecimento. Por mês, 2,1 milhões de pessoas visitam o blog da PloS.

A Biblioteca Central da Universidade Federal do Rio Grande do Sul ${ }^{60}$ utiliza seu blog para republicar conteúdos de diversos assuntos, geralmente relacionados com o fazer científico e normas.

A característica básica dos blogs é a de que seu conteúdo, na maioria, é gratuito e acessível a qualquer interessado, no entanto, necessita conhecer o endereço para encontra-lo na web. A linguagem utilizada é outro fator impactante ao que diz respeito aos blogs, de forma direta e informal, o blogueiro visa comunicar-se com seus leitores por meio dos materiais publicados neste ambiente, facilitando o entendimento do assunto.

53 ALDO BARRETO. Blog. 2018. Disponível em: <http://avoantes. blogspot.com.br/>

54 RONALDO MOTA. Blog. 2018. Disponível em: < http:// teiaeducacional.blogspot.com.br/>

55 CÉLIA DIAS. Blog. 2018. Disponível em: <http://fontesgerais.blogspot. com.br $>$

56 Ursula Blattmann. 2018. Blog. Disponível em: <http://bib-ci.wikidot. com/system:page-tags-list >

57 ScIELO: 2018. Disponível em: <http://blog.scielo.org/>

58 FEEDSPOT. 2018. Disponível em: <https://blog.feedspot.com/science blogs/>

59 BLOG PLoS. 2018. Disponível em: <http://blogs.plos.org/>

60 Biblioteca Central da UFRGS. Blog. 2018. Disponível em: <https:// www.ufrgs.br/blogdabc/category/acesso-aberto/>
O ponto negativo é que qualquer um pode postar qualquer coisa a respeito do que quiser, já que esse tipo de publicação não respeita a um formato, normas ou comitê de ética. No entanto, cabe ao leitor filtrar blogs e conteúdos relevantes, os que dispõe de fontes a respeito do assunto publicado, ou que autor seja uma autoridade no assunto do qual esteja apresentando.

\section{CONCLUSÕES}

O acesso aberto propicia amplo compartilhamento do conhecimento. Neste cenário a informação ganha um lugar de destaque, ela passa a ser o insumo entre autores e organizações produtoras, ampliando o fluxo informacional, principalmente as que estão nas redes e canais de comunicação disponíveis na internet de forma gratuita.

Segundo Castells (2005, p. 108), "informações circulam pelas redes: redes entre empresas, redes dentro de empresas, redes pessoais e redes de computadores". É nesses ambientes informacional, das relações, objetivos e áreas que desencadeia a ampla disseminação da informação, fonte básica para o desenvolvimento científico e social.

O altruísmo da comunidade científica mobilizou organismos nacionais e internacionais e da sociedade, em desenvolver serviços e sistemas informacionais de acesso aberto para a publicação científica, isso se deu por dois motivos: econômico - que requer acesso gratuito da publicação científica, e, legal - no que tange ao autor e instituição financiadora utilizar de mecanismos que viabilizem o livre acesso do conteúdo científico, sem custos em seu acesso.

Para Araújo (2018, p.17) "A promoção e divulgação de informação científica e de produtos da ciência estão adquirindo uma nova dimensão com as redes e mídias sociais que passam a ser espaços de aproximação não só entre os periódicos e sua comunidade de autores e leitores, mas se estendendo a público cada vez maior".

O acesso aberto ganhou um vasto espaço na web, lá a visibilidade se torna maior que apenas na comunidade científica, não se faz mais ciência para cientistas, mas sim para toda sociedade, e esse é o fator que mobiliza a criação e manutenção de fontes especializadas de acesso 
aberto por pessoas, instituições ou organismos sem fins lucrativos, para preservar, disseminar e promover o acesso ao conteúdo científico por meio da internet para toda sociedade.

O que vimos neste levantamento foi a existência de inúmeras fontes especializadas de acesso aberto, apresentamos 71, mas existem muito mais, elas ganham espaço cada vez maior no cotidiano científico e social, estejam em canais formais ou informais, desde que possam estar acessíveis, são passíveis de ser usada, compartilhadas, propagadas e citadas por pesquisadores em novos estudos e também pela sociedade quando acessa e compartilha, é disseminação involuntária da informação.

As fontes de acesso aberto mais comuns, ou de maior quantidade, foram as: bibliotecas digitais, base de dados e diretórios que continham coleções inteiras de acesso aberto. Essas fontes foram bastante expressivas nos levantamentos feitos para o referido estudo.

Cabe ressaltar que não há conhecimento de fontes de informação comerciais que estejam disponíveis de open access, são dados estratégicos e vendáveis, por isso, encontram-se em plataformas comerciais que requer pagamento para a obtenção e acesso.

Artigo recebido em 26/02/20I8 e aceito para publicação em II/05/20I8

\section{SPECIALIZED OPEN ACCESS INFORMATION SOURCES}

ABSTRACT This descriptive survey article deals with specialized sources of open access information. Applies the literature review with a bibliographical and documentary survey. In order to verify the existence of specialized sources of open access. It serves as a basis for reflections on the use and propagation of open access sources. Data and examples from specialized sources were collected on: Digital Library, Database, Directories, Portals, Repositories, Metabuscadores and Blogs. It is concluded that, open access facilitates the sharing of scientific and strategic information, this scenario permeates the use of these sources by the scientific community and all society, with access to the web networks. It has been found that the use of digital libraries, database and directories containing sources of open access is increasing.

Keywords: $\quad$ Sources of specialized information. Open access. Formal and informal communication channels

\section{REFERÊNCIAS}

ALMADA, Larissa. Blogs: portas abertas para as marcas na cibercultura. Disponível em: <http:// revistacomsoc.pt/index.php/comsoc/article/ view/896/856> Acesso em: 04 fev. 2018

ARAÚJO, Carlos Alberto Ávila. O conceito de informação na Ciência da Informação. Inf. \& Soc.:Est., João Pessoa, v.20, n.3, p. 95-105, set./ dez. 2010.

ARAÚJO, Ronaldo Ferreira. Marketing científico digital e métricas de mídias sociais: indicadoreschave de desempenho de periódicos no Facebook. Inf. \& Soc.:Est., João Pessoa, v.28, n.1, p. 7-22, jan./abr. 2018.
ARAÚJO, Paula Carina de. O Blog “Na Era Da Informação" Como Ferramenta De Compartilhamento De Informação, Conhecimento E Para A Promoção Profissional. Disponível em: <https://revista.acbsc.org.br/racb/article/ view/676> Disponível em: 04 fev. 2018

ARBIX, Glauco. Investimento em inovação: Finep e os pesquisadores brasileiros. Jornal em discussão, Senado, Brasília, 07 nov. 2012. Disponível em: <http://www.senado.gov. $\mathrm{br} /$ noticias/Jornal/emdiscussao/inovacao/ investimento-inovacao-tecnologica-fineppesquisadores-brasil.asp $x>$.

BABALHAVAEJI, Fahimeh; FARHADPOOR, Mohammad Reza. Information source 
characteristics and environmental scanning by academic library managers. Information Research, v.18, n.1, mar. 2013. Disponível em:

<http://www.informationr.net/ir/18-1/ paper568.html\#.V6IWy_krKUk>. Acesso em: 07 jan. 2016.

BALLER, Silja; DUTTA, Soumitra; LANVIN, Bruno (Ed.). The Global Information Technology Report 2016: Innovating in the Digital Economy. Word Economic Forum: INSEAD: University Johnson, 2016. Disponível em: $\quad<$ http://www3.weforum.org/docs/ GITR2016/WEF_GITR_Full_Report.pdf>. Acesso em: 15 maio 2016.

BATTLES, Mathew. A conturbada história das bibliotecas. São Paulo: Planeta, 2003.

BORGES, Mônica Erichsen Nassif. O essencial para a gestão de serviços e produtos de informação. Revista Digital de Biblioteconomia e Ciência da Informação, Campinas, v. 5, n. 01, p. 115128, jul./dez., 2007.

BRASIL. PPA-Plano Plurianual 2016-2019: Desenvolvimento, Produtividade e Inclusão Social. Brasília: Ministério do Planejamento, Orçamento e Gestão: Secretária de Planejamento e Investimento Estratégico. 2015. Disponível em: <http:/ / www.planejamento.gov.br/secretarias/ upload/arquivo/spi-1/ppa-2016-2019/ppa-20162019-ascom-3.pdf>. Acesso em: 09 jun. 2016.

BRASIL. Lei n. 13.243 de 11 de janeiro de 2016. Dispõe sobre estímulos ao desenvolvimento científico, à pesquisa, à capacitação científica e tecnológica e à inovação Diário Oficial [da] União, Brasília, DF, 12 jan. 2016. Disponível em: <http://www.planalto.gov.br/ccivil_03/_ ato2015-2018/2016/lei/113243.htm>. Acesso em: 6 jun. 2016.
CAMARGO, Liriane Soares de Araújo; VIDOTTI, Silvana, Aparecida Borsetti Gregório. Arquitetura da Informação para repositórios digitais. In: SAYÃO, Luis et al (Orgs.) Implantação e gestão de repositórios institucionais: políticas, memória, livre acesso e preservação. Salvador: EDUFBA, 2009. p. 55-82

CAMPELLO, Bernadete; CALDEIRA, Paulo da Terra (Org.). Introdução às fontes de informação. 2. ed. Belo Horizonte: Autêntica, 2008.

CASTELLS, Manuel. Aula Magna: Os efeitos da informação em rede. Florianópolis: UDESC, 14 maio, 2015. (Informação verbalizada). Disponível em: <http:/ / www.udesc.br/?idNoticia=12925>. Acesso em: 20 jun. 2015.

CASTELLS, M. A sociedade em rede. São Paulo: Editora Paz e Terra, 8. ed., 2005.

CAVALCANTI, Marcos. Inovação, ciência e tecnologia a persistência no erro. Inteligência Empresarial, Rio de Janeiro, 31 maio, 2016. Disponível em: <http:// crie-inteligenciaempresarial.blogspot.com. br/2016/05/inovacao-ciencia-e-tecnologia. html>. Acesso em: 02 jun. 2016.

CENDÓN, Beatriz Valadares. Sistemas e redes de informação. In: CENDÓN, Beatriz Valadares et al. Ciência da Informação e Biblioteconomia: Novos Conteúdos e espaços de atuação. Belo Horizonte: Editora UFMG, 2005, 143 p. Disponível em: <https:/ /www.researchgate.net/ publication/259077574_Sistemas_e_redes_de_ informacao>

CERVO, Amado Luiz; BERVIAN, Pedro Alcino. Metodologia científica. 5. ed. São Paulo: Prentice Hall, 2002.

CRESWELL, John W.; PLANO CLARK, Vicki L. Pesquisa de métodos mistos. 2. ed. Tradução de Magda França Lopes. Porto Alegre: Penso, 2013, 288p. 
COSTA, Luana Priscila; SILVA, Terezinha Elisabeth da. Repositório multimídia: estrutura hipertextual e avaliação hipermediática. In: SILVA, Terezinha Elisabeth da (Org.). Interdisciplinaridade e Transversatilidade. Recife: NÉCTAR, 2008. p. 145-166.

CUNHA, Murilo Bastos da. Para saber mais: fontes de informação em ciência e tecnologia. 2. ed. Brasília: Briquet de Lemos / Livros, 2016.

CUNHA, Murilo Bastos da; CAVALCANTI, Cordélia Robalinho de Oliveira. Dicionário de Biblioteconomia e Arquivologia. Brasília, DF: Brinquet de Lemos, 2008.

DAHLANDER, Linus; GANN, David. How open is innovation? Reserarch Policy, London, v. 39, n. 6, p. 699-709, 2010. doi: 10.1016/j. respol.2010.01.013. Acesso em: 02 jun. 2016.

DI LUCCIO, Flávia; COSTA, Ana Maria Nicolacida. Blogs: De Diários Pessoais a Comunidades Virtuais de Escritores/leitores. Disponível em: <http://www.scielo.br/pdf/ pcp/v30n1/v30n1a10> Acesso em: 04 fev. 2018.

DRUCKER, P. Sociedade pós-capitalista. São Paulo: Editora Pioneira, 1999.

ELKINGTON, Nancy E.; MASSIE, Dennis. The changing nature of international resource sharing: risks and benefits of collaboration. Interlending \& Document Supply, v.27, n.4, p.148-154, 1999.

FERREIRA, Sueli Mara S.P. Fontes de informação em tempos de Acesso Livre/Aberto. In: GIANNASI-KAIMEN, Maria Júlia; CARELLI, Ana Esmeralda. Recursos Informacionais para compartilhamento da informação: redescobrindo acesso, disponibilidade e uso. Rio de Janeiro: e-papers, 2007. p.141-174

GÓMEZ, Jaime; SALAZAR, Idana; VARGAS, Pilar. (2016) Sources of Information as Determinants of Product and Process Innovation.
PLoS ONE, Califórnia, v.11, n. 4, abr. 2016. doi:10.1371/journal.pone.0152743. Acesso em: 09 jun. 2016.

GOAP. Brasil. 2017. Disponível em: <http:// www.unesco.org/new/en/communicationand-information/portals-and-platforms / goap/access-by-region/latin-america-and-thecaribbean/brazil/>

GUINCHAT, Claire; MENOU, Michel. Introdução geral às ciências e técnicas da informação e documentação. 2. ed. Brasília: IBICT, 1994.

HENRIQUE, Luiz Cláudio Junqueira. Inovação e informação. 2006. 225 f. Tese (Doutorado em Ciência da Informação) - Escola de Ciência da Informação, Universidade Federal de Minas Gerais. Belo Horizonte, 2006.

HORLAND, Birger; ANDERSEN, Jack; SØNDERGAARD, Trine Fjordback. UNISIST model and knowledge domains. In: Encyclopedia of library and information science: First Update Supplement. New York: CRC Press LLC, 2005. p. 129 - 135. Disponível em: Acesso em: 11 ago. 2015.

MATHEUS, Renato Fabiano. Rafael Capurro e a filosofia da informação: abordagens, conceitos e metodologias de pesquisa para a Ciência da Informação. Perspectivas em Ciência da Informação, v. 10, n. 2, p. 140-16, maio, 2005.

MARTINS, Wilson. A palavra escrita: história do livro, da imprensa e da biblioteca. 3. ed. São Paulo: Ática, 2002.

$\begin{array}{lccr}\text { MINISTÉRIO } & \text { DA } & \text { CIÊNCIA, } \\ \text { TECNOLOGIA } & \text { E } & \text { INOVAÇÃO. } \\ \text { Estratégia } & \text { Nacional de } & \text { Ciencia, } \\ \text { Tecnologia } & \text { e Inovação } & \text { 2012-2015: }\end{array}$
Balanço das atividades estruturantes 2011. Brasília: MCTI, 2012. Disponível 
em: $\quad<$ http://www.mct.gov.br/upd blob/0218/218981.pdf>. Acesso em: 20 dez. 2015.

MOORE, Valerie A. Public Perception of the Differences Between Printed and Electronic Books: A Content Analysis. Chapel Hill, Carolina do Norte, 2014. Disponível em: <https://cdr.lib.unc. edu/record/uuid:05860de6-ef2b-481c938c-a57ea25626e5>. Acesso em: 05 fev. 2016

MUELLER, Suzana P. M. A ciência, o sistema de comunicação científica e a literatura científica. In: CAMPELLO, Bernadete Santos; CENDÓN, Beatriz Valadares; KREMER, Jeannette Marguerite (Org.). Fontes de informação para pesquisadores e profissionais. Belo Horizonte: Ed. UFMG, 2000, 319 p.

MURAKAMI, Tiago Rodrigo Marçal; FAUSTO, Sibele. Panorama atual dos Repositórios Institucionais das Instituições de Ensino Superior no Brasil. Disponível em: <http:// www.revistas.usp.br/incid/article/ view/69327/71820> Acesso em: $02 \mathrm{fev}$. 2018

NORTE, Mariângela Braga. Glossário de termos técnicos em Ciência da Informação. São Paulo: Cultura Acadêmica, 2010.

ORTEGA, Cristina Dotta. Relações históricas entre Biblioteconomia, Documentação e Ciência da Informação. DataGramaZero, Revista de Ciência da Informação, v.5, n.5, out. 2004.
PARRILLI, Mario Davide; HERAS, Henar Alcalde. STI and DUI innovation modes: Scientific-technological and context-specific nuances. Research Policy, Elsevier, n. 45 p.747756, 2016. doi.org/10.1016/j.respol.2016.01.001

PACKER, Abel, L. et al. (Org.). SciELO 15 anos de Acesso Aberto: Um estudo analítico sobre Acesso Aberto e comunicação científica. Paris: UNESCO, 2014, 188 p. ISBN 978-923701-237-6. Disponível em: <http://dx.doi. org/10.7476/9789237012376>. Acesso em: 17 jul. 2017.

PEREZ- RIOJA, José Antônio. El libro y la biblioteca. Barcelona: Salvat, 1952.

SANTOS, Josiel Machado. O Processo Evolutivo das Bibliotecas da Antiguidade ao Renascimento. Revista Brasileira de Biblioteconomia e Documentação. São Paulo, v.8, n.2, p. 175-189, jul./dez. 2012.

RAMPAZZO, Lino. Metodologia científica: para alunos dos cursos de graduação e pós-graduação. 7. ed. São Paulo: Loyola, 2013, 154p.

ROWLEY, Jennifer. A Biblioteca Eletrônica. Brasília: Briquet de Lemos, 2002.

ROZADOS, H. B. F. Indicadores como ferramenta para gestão de serviços de informação tecnológica. 2004. Tese (Doutorado em Ciência da Informação) - Faculdade de Biblioteconomia e Comunicação, Universidade Federal do Rio Grande do Sul, Porto Alegre, 2004.

SILVA, Edna Lúcia da. Compartilhamento de recursos e o papel das redes de informação. Revista de Biblioteconomia de Brasília, Brasília, v.14, n.2, p.209-225, jul./dez. 1986.

SUGAHARA, Cibele R.; JANNUZZI, Paulo de M. Estudo do uso de fontes de informação para inovação tecnológica na indústria brasileira. 
Ciência da Informação, Brasília, v. 34, n. 1, p.4556, jan./abr., 2005.

TOMAÉL, Maria Inês. Redes de informação: o ponto de contato dos serviços e unidades de informação no Brasil. Informação \& Informação, Londrina, v. 10, n. 1-2, p. 5-30, dez. 2005. Disponível em: <http://www.uel.br/ revistas/uel/index.php/informacao/article/ view/1611/1366>. Acesso em: 29 jun. 2016.
UNESCO. UNESCO Science Report: towards 2030. França, Paris: UNESCO, 2015. Disponível em: <http://unesdoc.unesco.org/ images/0023/002354/235406e.pdf>. Acesso em: 04 maio 2016.

WOMBLE, Katie G. Collaboration between Library Publishing Services and University Presses. Chapel Hill, Carolina do Norte, 2015. Disponível em: <https://cdr.lib.unc.edu/ indexablecontent/uuid:4f8e4c24-5273-444d-a1ab7f3395a6273b?dl=true>. Acesso em: 06 jan. 2018. 